\title{
Safety and efficacy of amine-containing methacrylate polymers as nonviral gene delivery vectors
}

\author{
Noura H. Abd Ellah ${ }^{1,3}$, Sarah J. Potter ${ }^{1}$, Leeanne Taylor ${ }^{2}$, Neil Ayres², Mona M. Elmahdy ${ }^{3}$, Gihan N. Fetih ${ }^{3}$, El-Sayed A. Ibrahim³ and \\ Giovanni M. Pauletti ${ }^{*}$
}

*Correspondence: gm.pauletti@uc.edu

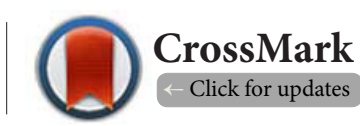

'James L. Winkle College of Pharmacy, University of Cincinnati, Cincinnati, OH 45267, USA.

2Department of Chemistry, University of Cincinnati, Cincinnati, OH 45221, USA.

${ }^{3}$ Faculty of Pharmacy, Assiut University, 71515 Assiut, Egypt.

\begin{abstract}
Background: Nonviral polymeric delivery systems are explored to enhance clinical development of nucleic acids as therapeutic entities for effective management of debilitating conditions such as cancer. This study was to compare safety and efficacy of quaternary amine-containing methacrylate polymer Eudragit ${ }^{\circledR} \mathrm{RL}$ PO (ERL) and poly [ $N$-(2-hydroxypropyl)methacrylamide $]$-poly $(N, N$-dimethylaminoethyl methacrylate) copolymer (pHPMA-b-pDMAEMA), which contains secondary and tertiary amines, as effective gene carriers.

Methods: Polyplexes of pAcGFP1-C1 with ERL or pHPMA-b-pDMAEMA were fabricated at different $\mathrm{N} / \mathrm{P}$ ratios. Formation of DNA/catiomer nanostructures was monitored by ethidium bromide intercalation and agarose gel retardation. Particle size, zeta potential and cytotoxicity of different polyplexes were characterized. Transfection efficiency in presence and absence of serum was assessed using confocal microscopy.

Results: pHPMA-b-pDMAEMA demonstrated at least a 10-fold greater DNA condensation capacity per weight unit than ERL. However, DNA intercalation with pHPMA-b-pDMAEMA was reduced in presence of serum-free cell culture media, whereas polyplex formation with ERL was equivalent in phosphate-buffered saline, $\mathrm{pH} \mathrm{7.4}$ and serum-free cell culture media. Cellular safety of HeLa cells was not compromised by polyplexes fabricated with either polymer up to $\mathrm{N} / \mathrm{P}=4$. However, ERL alone was more toxic. In absence of serum, pHPMA-b-pDMAEMA polyplexes at $\mathrm{N} / \mathrm{P}=4$ induced equivalent transgene expression as control TurboFect ${ }^{\mathrm{TM}}$ polyplexes. In contrast, ERL-containing nanoassemblies failed to produce measurable transgene expression. Inclusion of serum significantly decreased transfection efficiency of pHPMA-b-pDMAEMA-containing polyplexes by $\sim 30 \%$ at $\mathrm{N} / \mathrm{P}=4$ and $\sim 50 \%$ at $\mathrm{N} / \mathrm{P}=2$.

Conclusion: Polyplexes fabricated with secondary and tertiary amine-containing pHPMA-b-pDMAEMA copolymer represent more effective gene delivery systems than nanoassemblies composed of quaternary amine-containing ERL and should be further explored for clinical applications.
\end{abstract}

Keywords: Transfection, cell survival, polymethacrylic acid, polyplex, Eudragit ${ }^{\circledR}$ RL PO

\section{Introduction}

Recent advances in molecular understanding of patho-physiological processes continue to fuel great interest in clinical exploration of gene therapy. Increased safety concerns associated with highly effective viral vectors mandate development of novel nonviral gene carriers in order to revolutionize clinical management of debilitation genetic disorders such as cystic fibrosis, diabetes, hemophilia, and cancers [1]. Due to the high molecular weight and negative charge associated with genetic material, transfer of these therapeutic moieties across biological membranes is limited. Consequently, one of the major challenges of gene therapy is to deliver therapeutically active genetic material into desired target cells. To enhance stability and efficiency of gene delivery systems, genetic material is 
generally encapsulated into a vector that protects the payload from degradation and, simultaneously, facilitates effective intracellular delivery. Viral vectors were demonstrated to achieve high transfection efficiency in vitro and in vivo. Unfortunately, clinical development of virus-based gene delivery systems is restricted due to undesired immune responses and cellular toxicity $[\mathbf{1 , 2}]$. Nonviral vectors, in contrast, are considered less immunogenic and generally exhibit favorable safety profiles [2]. Fundamental to the design of a synthetic gene delivery system is its ability to neutralize the negative charge of genetic material in order to prevent charge repulsion at the anionic cell surface. Furthermore, synthetic carriers must successfully condense the bulky DNA structure to the nanoscales for effective cellular internalization and to protect nucleic acids from enzymatic degradation mediated by both extra- and intracellular nucleases [3]. Cationic polymers and lipids spontaneously form electrostatically-driven association complexes (i.e., polyplexes or lipoplexes) when combined with DNA/RNA structures [4]. Previous research demonstrated that gene delivery systems carrying excess positive charge interact more efficiently with negatively charged cell membrane components such as proteoglycans and glycosaminoglycans, thus, enhancing cellular uptake and transfection [5]. However, it was also reported that these highly positive charged comp-lexes might be disrupted before reaching their targets due to the effect of other charged molecules in the serum or the extracellular matrix [6]. The stoichiometric ratio of positively charged amine groups in a cationic polymer and negatively-charged phosphate groups in DNA/RNA moieties (i.e., N/P ratio) is a key determinant of effective gene delivery due to its impact on particle size and zeta potential of nanoassemblies [7].

At the cellular level, safety and efficiency of these carriers are strongly affected by the architecture of the polymer used [8]. The amino groups in cationic polymers play a critical role in defining physicochemical properties of association complexes and transfection efficacy $[\mathbf{9}, \mathbf{1 0}]$. In particular, secondary and tertiary amine groups present in the polymer backbone are predicted to enhance endosomal escape due to the "proton sponge" effect, which is a prerequisite for transfer of genetic material into the nucleus after cell internalization via endocytosis $[11,12]$. The objective of this study was to compare safety and efficacy of nonviral gene delivery systems fabricated with the commercially available, quaternary amine-containing ERL and the secondary/tertiary amine-containing pHPMA-bPDMAEMA, which was synthesized by RAFT polymerization (Figure 1). ERL is a FDA-approved excipient and widely used in marketed pharmaceutical products to control $\mathrm{pH}$-independent drug release. Consequently, it is one of the logical first choices of excipients when considering formulation approaches for gene delivery systems as its safety profile in humans is already established [13]. pHPMA-b-pDMAEMA is a representative examples of the growing class of experimental, water-soluble diblock copolymers that are synthesized by various polymer chemists to overcome apparent safety and efficiency challenges associated with existing catiomers.

Chemically, pHPMA-b-pDMAEMA contains $\sim 30 \%$ secondary and tertiary amino groups per gram that are predicted to greatly enhance endosomal escape of internalized polyplexes and, consequently, increase transfection efficiency [12]. In contrast to PDMAEMA, which was demonstrated to induce substantial cytotoxic effects [14], copolymerization with the hydrophilic pHPMA moiety significantly increased cellular safety [12]. For formulators, however, the lack of FDA-approval for pHPMA-b-pDMAEMA or similar experimental copolymers is a significant concern, as time- and cost-intensive safety studies must be completed before initial clinical evaluation with this novel excipient can begin. This strategy is only justified if the use of a novel excipient is predicted to dramatically improve safety and/or efficacy of the formulation in patients.

\section{Materials and methods Materials}

The poly [N-(2-hydroxypropyl)methacrylamide]-poly $(\mathrm{N}, \mathrm{N}$ -

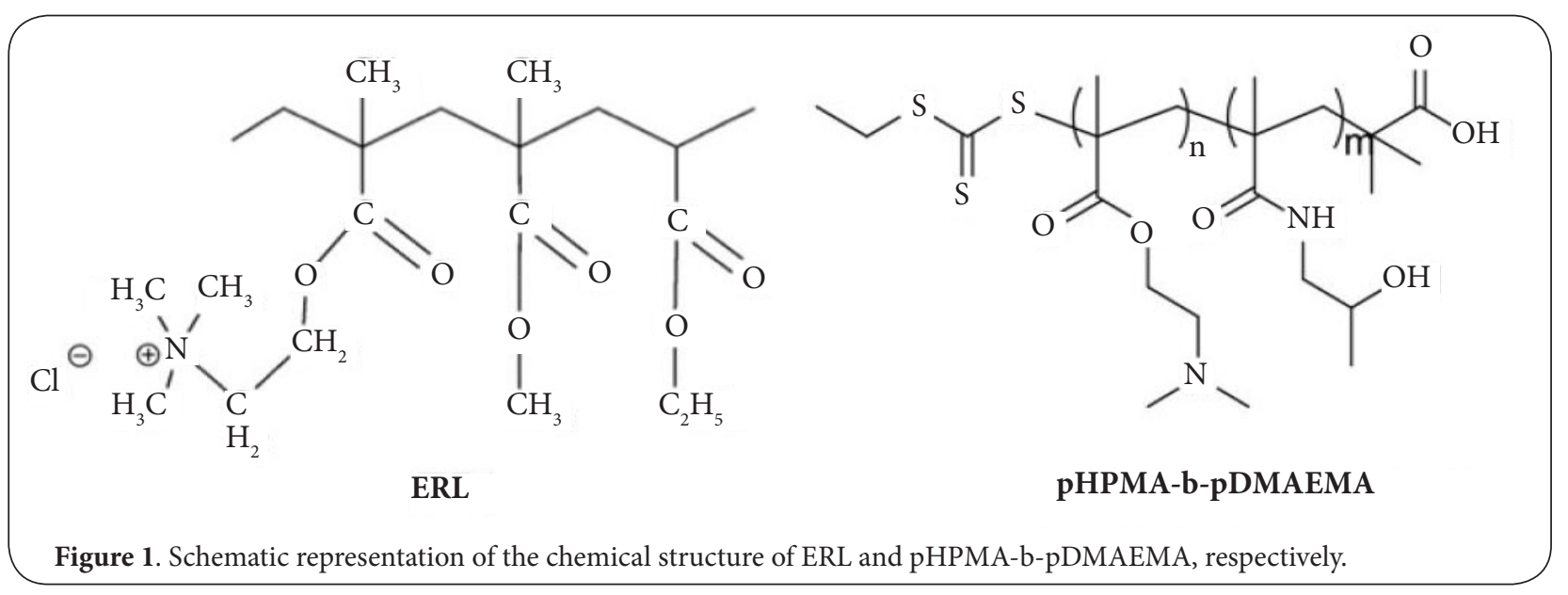


dimethylaminoethyl methacrylate) diblock copolymer (pHPMA-b-pDMAEMA) was synthesized by reversible additionfragmentation chain transfer (RAFT) polymerization using a procedure adapted from Duvall and colleagues [15]. The average molecular weight of pHPMA-b-pDMAEMA determined by gel permeation chromatography was $=21.2 \mathrm{kDa}$. Eudragit ${ }^{\circledR} \mathrm{RL}$ PO (ERL) was a gift from Evonik Industries (Parsippany, NJ). The pAcGFP1-C1 expression plasmid was obtained from Clontech Laboratories (Mountain View, CA) and amplified according to the manufacturer's protocols. TurboFect ${ }^{\mathrm{TM}}$ Transfection Reagent, DRAQ5 $5^{\mathrm{TM}}, 1 \mathrm{~kb}$ DNA ladder, Dulbecco's modified Eagle's medium (DMEM), phosphate-buffered saline pH 7.4 (PBS), agarose, agarose gel loading dye, ethidium bromide (EtBr), Tris/EDTA (TE) buffer, and cell supplements such as trypsin/ EDTA, penicillin-streptomycin, L-glutamine, and non-essential amino acids were purchased from ThermoFisher Scientific (Pittsburgh, PA). Tris-acetate-EDTA (TAE) running buffer and CellTiter-Glo ${ }^{\circledR}$ cytotoxicity assay kit were purchased from Promega (Madison, WI). Branched polyethylenimine $25 \mathrm{kDa}$ (PEI25k) was purchased from Sigma Aldrich (St. Louis, MO). Heat-inactivated fetal bovine serum (FBS) was obtained from Atlanta Biologicals (Atlanta, GA). All other chemicals were of analytical grade and used as received.

\section{Cell culture}

HeLa cells were obtained from the American Type Culture Collection (Manassas, VA) and maintained at $37^{\circ} \mathrm{C}$ in a humidified $5 \%(\mathrm{v} / \mathrm{v}) \mathrm{CO}_{2}$ atmosphere using DMEM supplemented with $10 \%(\mathrm{v} / \mathrm{v}) \mathrm{FBS}, 1 \%(\mathrm{w} / \mathrm{v})$ L-glutamine, $100 \mathrm{lU} / \mathrm{ml}$ penicillin, 100 $\mu \mathrm{g} / \mathrm{ml}$ streptomycin, and $1 \%(\mathrm{v} / \mathrm{v})$ non-essential amino acids.

\section{Ethidium bromide intercalation}

The ability of cationic polymers to condense pDNA was monitored by fluorescence quenching of the pDNA-EtBr interaction as described previously [16]. $1 \mu \mathrm{g}$ of pDNA suspended in $50 \mu \mathrm{L}$ of either PBS or serum-free DMEM (SFM) was combined with $50 \mu \mathrm{L}$ of an aqueous $\mathrm{EtBr}$ solution $(5 \mu \mathrm{g} / \mathrm{mL})$ and incubated at room temperature (RT) for $15 \mathrm{~min}$. Polymer aliquots were sequentially added and incubated for $30 \mathrm{~min}$ at RT before fluorescence emission was quantified at $\lambda=590 \mathrm{~nm}$ ( $E X=544$ $\mathrm{nm}$ ) using the POLARstar microplate reader (BMG Labtech, Cary, NC).

\section{Agarose gel retardation}

Electrophoretic mobility of polymer/pDNA complexes was determined by agarose gel electrophoresis $[17,18]$. Catiomer/ pDNA complexes containing $0.4 \mu \mathrm{g}$ of pAcGFP1-C1 were combined with $2 \mu \mathrm{L}$ of the gel loading dye, and $20 \mu \mathrm{L}$ of this suspension were loaded onto a $0.5 \%(\mathrm{w} / \mathrm{v})$ agarose gel. pAcGFP1-C1 plasmid without polymer was used as a control. Separation was carried out for $100 \mathrm{~min}$ at $90 \mathrm{~V}$ in TAE running buffer using the Power Pac 200 (Bio-Rad, Hercules, CA). Following electrophoresis, gels were stained for 40 min using a $0.005 \%$ $(\mathrm{v} / \mathrm{v})$ aqueous EtBr solution. pDNA bands were visualized after 30 min destaining in water at $\lambda=254 \mathrm{~nm}$ using the UVP Bioimaging System (UVP, Upland, CA).

\section{Polyplexes fabrication}

Association complexes between pAcGFP1-C1 and pHPMA-bPDMAEMA, ERL were formed by combining $1 \mu \mathrm{g}$ of pAcGFP1-C1 with various polymer amounts in PBS and SFM resulting in polyplexes with N/P ratios up to 4 . Electrostatic association was allowed for $1 \mathrm{hr}$ at RT with occasional vortexing (20 seconds every 15 minutes). Stock solutions of ERL were prepared in $95 \%(\mathrm{v} / \mathrm{v})$ ethanol. For subsequent experiments, final ethanol concentration was $\leq 1 \%(\mathrm{v} / \mathrm{v})$. pHPMA-b-pDMAEMA solutions were directly prepared in aqueous vehicles.

\section{Physicochemical properties of polyplexes}

Particle size distribution and zeta potential of fabricated polyplexes were estimated by dynamic laser light scattering using the Zetasizer Nano-ZS (Malvern Instruments, Worcestershire, U.K.) according to the manufacturer's instructions. All particle size values reported in this study refer to the equivalent hydrodynamic diameter.

\section{Cellular safety}

Viability of HeLa cells after exposure to the various polymers in the presence and absence of PAcGFP1-C1 was quantified using the CellTiter-Glo ${ }^{\circledR}$ luminescent assay, which measures total cellular ATP. For these experiments, HeLa cells were seeded in white 96 -well plate at density of $1 \times 10^{4}$ cells/well. Following an overnight attachment, cells were washed with prewarmed SFM and incubated for $4 \mathrm{hrs}$ at $37^{\circ} \mathrm{C}$ in the presence of various polyplex or polymer concentrations. Subsequently, cells were washed using FBS-containing DMEM and incubated for additional $44 \mathrm{hrs}$ in maintenance media. Following addition of the CellTiter-Glo ${ }^{\circledR}$ reagent, luminescence was quantified using the POLARstar microplate reader (BMG Labtech, Cary, NC). Cells incubated with a $1 \%(\mathrm{v} / \mathrm{v})$ Triton X-100 solution prepared in PBS were used as negative control. Cell viability was normalized to vehicle-treated controls.

\section{Acid-base titration}

Endosomal buffering capacity of pHPMA-b-pDMAEMA and ERL was estimated by acid-base titration as described by Cai and colleagues [19]. Briefly, polymers were dissolved or suspended at $20 \mathrm{mg} / \mathrm{L}$ in $50 \mathrm{mM} \mathrm{NaCl}$, and $\mathrm{pH}$ value of this solution was adjusted to $\mathrm{pH} 10$ using $0.1 \mathrm{~N} \mathrm{NaOH}$. Acid-base titration was accomplished by incremental addition of $10 \mu \mathrm{L}$ aliquots of $0.1 \mathrm{~N} \mathrm{HCl}(150 \mu \mathrm{L}$ total). The $\mathrm{pH}$ value was determined at RT following each addition. PEI25k was used as a positive control.

\section{In vitro transfection efficiency}

HeLa cells were seeded in 16-well chamber slides at density of $1 \times 10^{4}$ cells/well. Following an overnight attachment, cells were washed with prewarmed SFM and incubated for 4 hrs at $37^{\circ} \mathrm{C}$ with polyplexes suspended in SFM $(0.2 \mu \mathrm{g}$ DNA/well). Naked 
Aba Ellah et al. Journal of Pharmaceutical Technology \& Drug Research 2014,

http://www.hoajonline.com/journals/pdf/2050-120X-3-2.pdf

doi: $10.7243 / 2050-120 \mathrm{X}-3-2$

DNA and the transfection reagent TurboFect ${ }^{\mathrm{TM}}$ were used as controls. Subsequently, cells were washed with FBS-containing DMEM and incubated for additional $44 \mathrm{hrs}$ in maintenance media to allow transgene expression. Cells were washed $3 x$ with PBS and counterstained with the red DRAQ5 nuclear stain. The percentage of positive, green fluorescent cells was determined in three randomly selected sections (Zeiss LSM510 Confocal Microscope, Zeiss, Germany). To assess the impact of serum on transfection efficiency, polyplexes were incubated in FBS-containing DMEM.

\section{Statistical analysis}

Experiments were performed at least in triplicate, and results are reported as mean \pm standard deviation (SD). Statistical difference among various treatment groups was assessed using one-way ANOVA or two-sided Student's $t$-test for pairwise comparison. A probability of $p<0.05$ was considered statistically significant (GraphPad Prism 6.0, GraphPad, San Diego, CA).

\section{Results and discussion \\ Polymer/pDNA interactions}

Polyplex formation is thermodynamically driven by electrostatic interactions between negatively charged phosphate groups of nucleic acids and positively charged amino groups present on the polymers [20]. To quantify the stoichiometric relationship of this interaction for each polymer, fluorescence quenching of $\mathrm{EtBr} / \mathrm{pDNA}$ complexes in the presence of various polymer amounts was measured. Decreasing fluorescence intensities determined after addition of increasing amounts of pHPMAb-pDMAEMA experimentally underlined the ability of this cationic polymer to electrostatically bind negatively charged pDNA in PBS and SFM (Figure 2A). pHPMA-b-pDMAEMA is estimated to contain on a molar basis $~ 30 \%$ cationic centers in form of secondary and tertiary amine groups. In PBS, effective condensation of $1 \mu \mathrm{g}$ of pDNA was achieved in the presence of $513 \mathrm{ng}$ of this diblock polymer $(\mathrm{N} / \mathrm{P}=1)$. These results were consistent with agarose gel retardation data where the fluorescence intensity of EtBr/pDNA bands associated with relaxed and coiled nucleic acid strands dramatically decreased following addition of polymer amounts $>128 \mathrm{ng}$ (Figure 2B). In the presence of $513 \mathrm{ng}$ of pHPMA-b-pDMAEMA (Figure 2B, Lane 4), electrophoretic mobility of EtBr/pDNA was visually absent suggesting effective pDNA condensation with this secondary and tertiary amine groups containing polymer $[16,19]$. In contrast, the stoichiometry of pDNA/pHPMA-b-pDMAEMA interactions in SFM was significantly different. Based on EtBr intercalation results (Figure 2A), it appears that the presence of media components interferes with effective condensation of pDNA with this cationic polymer. Addition of pHPMA-bpDMAEMA amounts $>0.5 \mu \mathrm{g}$ was only moderately successful in increasing $\mathrm{EtBr}$ displacement greater than $40 \%$. Even in the presence of $1.5 \mu \mathrm{g}$ of this polymer, electrostatic neutrality (i.e., $\mathrm{N} / \mathrm{P}=1$ ) was never reached. Agarose gel retardation assay confirmed the inability of pHPMA-b-pDMAEMA to fully

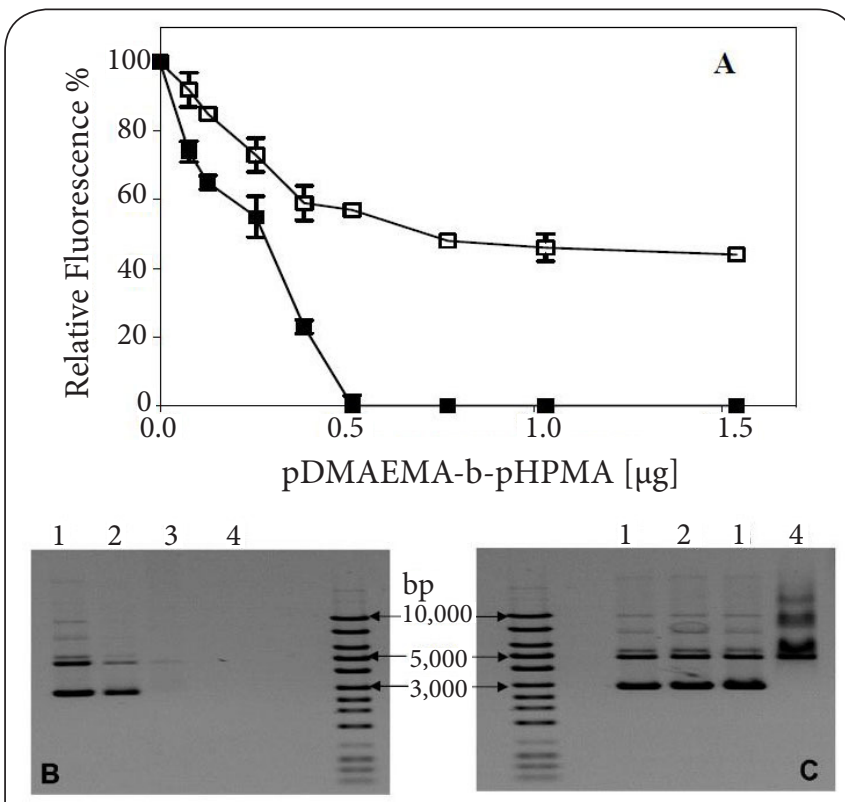

Figure 2. Vehicle effect on polyplex formation with pHPMA-b-pDMAEMA. EtBr displacement from pDNA in PBS ( $\square$ ) and SFM ( $\square$ ) was quantified in the presence of 0-1.5 $\mu \mathrm{g}$ of pHPMA-b-pDMAEMA using fluorescence spectrophotometry (Panel A). Results are shown as mean \pm SD $(n=3)$. Representative agarose gel pictures after electrophoretic separation of $\mathrm{pDNA} / \mathrm{pHPMA}$-bpDMAEMA polyplexes prepared at different mass ratios with $1 \mu \mathrm{g}$ of pAcGFP1-C1 in PBS and SFM are shown in Panel $\mathbf{B}$ and $\mathbf{C}$, respectively. Lane 1: DNA control, Lane 2: $128 \mathrm{ng}$ polymer, Lane 3: $256 \mathrm{ng}$ polymer, Lane 4: $513 \mathrm{ng}$ polymer.

condensate pDNA in SFM by the presence of bright, fluorescent EtBr-stained pDNA bands (Figure 2C). It is hypothesized that zwitterionic amino acids in SFM afforded electrostatic shielding of positively charged amine groups in the DMAEMA moieties, thereby reducing the pDNA condensation ability of this polymer $[\mathbf{2 1}, \mathbf{2 2}]$. Similar binding experiments were performed with ERL that contains on a molar basis $~ 10 \%$ cationic centers in form of quaternary ammonium groups [23]. Figure 3 summarizes the results of EtBr intercalation and agarose gel retardation assays performed with ERL. Increasing polymer amounts consistently reduced fluorescence signal of $\mathrm{EtBr} /$ pDNA suggesting efficient electrostatic interactions between the negatively charged pDNA and the positively charged ERL (Figure 3A). In PBS, complete quenching equivalent to $\mathrm{N} / \mathrm{P}=1$ was achieved using $7 \mu \mathrm{g}$ of ERL. Interestingly, the stoichiometry of pDNA displacement from EtBr in the presence of ERL was not affected by buffer compositions, most likely due to involvement of quaternary ammonium groups. The estimated amount of ERL required for fabrication of ionically balanced polyplexes with $1 \mu \mathrm{g}$ of pDNA was not significantly different between PBS and SFM ( $p=0.882)$. Agarose gel retardation assays confirmed these results where no electrophoretic mobility of pDNA was observed in the presence of $7 \mu \mathrm{g}$ of 


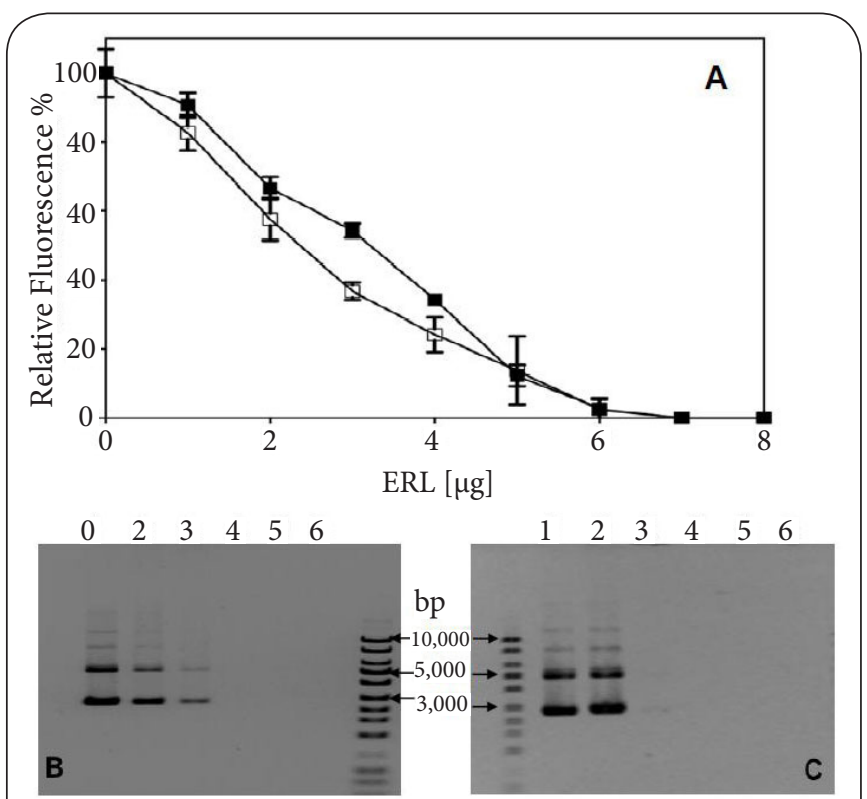

Figure 3. Vehicle effect on polyplex formation with ERL. EtBr displacement from pDNA in PBS ( $\square$ ) and SFM ( $\square$ ) was quantified in presence of 0-8 $\mu \mathrm{g}$ of ERL using fluorescence spectrophotometry (Panel A). Results are shown as mean \pm SD $(n=3)$. Representative agarose gel pictures after electrophoretic separation of $\mathrm{pDNA} / \mathrm{ERL}$ polyplexes prepared at different mass ratios with $1 \mu \mathrm{g}$ of pAcGFP1-C1 in PBS and SFM are shown in Panel B and C, respectively. Lane 1: DNA control, Lane 2: $1.75 \mu \mathrm{g}$ polymer, Lane 3: $3.5 \mu \mathrm{g}$ polymer, Lane 4: $7 \mu \mathrm{g}$ polymer, Lane 5: $14 \mu \mathrm{g}$ polymer, Lane 6: $28 \mu \mathrm{g}$ polymer.

ERL irrespective of the buffer system used to fabricate these polyplexes (Figures $\mathbf{3 B}$ and $\mathbf{3 C}$ ). The favorable condensation ability of pHPMA-b-pDMAEMA when compared to ERL may be the result of increased interactions between the increased number of cationic centers engineered in the polymer and negatively charged pDNA. In addition, the presence of amide group in HPMA moieties may facilitate greater intrapolymeric interactions [14].

\section{Physicochemical properties of polyplexes}

Cellular internalization of electrostatically stabilized polyplexes is a necessary prerequisite for successful gene delivery. Previous studies identified the critical relationship between particle size and cellular uptake rates [24]. Consequently, physicochemical properties such as size and zeta potential were quantified for polyplexes fabricated with pHPMA-bPDMAEMA and ERL at different stoichiometric ratios. Since pDNA/pHPMA-b-pDMAEMA condensation was incomplete (see Figure 2C), physiochemical properties of these polyplexes were only determined in PBS. The results summarized in Tables 1 and $\mathbf{2}$ indicate that the mean diameter of fabricated polyplexes becomes generally smaller in the presence of increasing polymer. At charge neutrality (i.e., $\mathrm{N} / \mathrm{P}=1$ ), polyplexes fabricated in PBS with pHPMA-b-pDMAEMA were significantly
Table 1. Physicochemical properties of pHPMA-b-pDMAEMA/ pAcGFP1-C1 polyplexes fabricated in PBS.

\begin{tabular}{lll}
\hline $\mathbf{N} / \mathbf{P}$ & Size $[\mathrm{nm}]$ & Zeta potential $[\mathrm{mV}]$ \\
\hline 0.25 & $192 \pm 66$ & $-9.2 \pm 8.5$ \\
0.5 & $235 \pm 17$ & $-3.9 \pm 0.6$ \\
1 & $144 \pm 2.9$ & $-0.3 \pm 0.5$ \\
2 & $111 \pm 1.4$ & $-2.7 \pm 2.1$ \\
4 & $104 \pm 3.0$ & $-2.0 \pm 3.0$ \\
\hline
\end{tabular}

Data are shown as mean \pm SD $(n=3)$

Table 2. Physicochemical properties of ERL/pAcGFP1-C1 polyplexes fabricated in PBS and SFM.

\begin{tabular}{l|llll}
\hline \multirow{2}{*}{ N/P ratio } & \multicolumn{2}{|c}{ Size [nm] } & \multicolumn{2}{c}{ Zeta potential [mV] } \\
\cline { 2 - 5 } & PBS & SFM & PBS & SFM \\
\hline 0.25 & $834 \pm 112$ & $764 \pm 73$ & $-33 \pm 4.0$ & $-28 \pm 3.0$ \\
0.5 & $732 \pm 37$ & $717 \pm 4.0$ & $-35 \pm 3.0$ & $-24 \pm 2.0$ \\
1 & $598 \pm 20$ & $617 \pm 28$ & $-5.0 \pm 1.0$ & $-1.3 \pm 0.7$ \\
2 & $366 \pm 8.0$ & $170 \pm 4.0$ & $+26 \pm 3.0$ & $+32 \pm 2.0$ \\
4 & $182 \pm 4.0$ & $115 \pm 6.0$ & $+26 \pm 2.0$ & $+30 \pm 0.0$ \\
10 & $163 \pm 5.0$ & $123 \pm 2.0$ & $+24 \pm 1.0$ & $+29 \pm 1.0$ \\
\hline
\end{tabular}

Data are shown as mean \pm SD $(n=3)$

smaller in size than corresponding nanoparticles prepared with ERL. It is predicted that greater density of positively charged amine groups in pHPMA-b-pDMAEMA induces more effective condensation of pDNA into electrostatically-stabilized nanoassemblies [25].

In addition to particle size, surface charge of polymer/pDNA nanoassemblies is recognized as an important determinant of cellular uptake. In general, positively charged composites are electrostatically attracted to negatively charged cell surfaces, which can augment cellular uptake [24]. However, the excessive positively charged nanoparticles are reported to induce greater cell membrane damage and increased platelet aggregation suggesting a less favorable safety profile [13]. The zeta potential of polyplexes fabricated with increasing polymer concentrations shifts towards the positive range due to neutralization of the negative charge associated with nucleic acids (Tables 1 and 2). The surface charge of ERL/pDNA nanoassemblies at $\mathrm{N} / \mathrm{P}<1$ was significantly more negative than that of pHPMA-b-pDMAEMA/pDNA polyplexes $(-20$ to $-30 \mathrm{mV}$ vs. -9 to $-4 \mathrm{mV}$, respectively). It is hypothesized that the greater presence of methacrylate moieties in ERL contributes to this difference in zeta potential. Following neutralization, however, pHPMA-b-pDMAEMA complexes prepared with excess cationic polymers $(N / P>1)$ failed to reach zeta potentials significantly greater than $0 \mathrm{mV}$. This may result from shielding effects induced by phosphate buffer ions that exhibit high affinity for primary amines present in pHPMA-b-pDMAEMA [26]. In addition, it is suggested that HPMA moieties may also contribute to charge shielding which is required to decrease the interaction with the negatively charged blood components, 
Aba Ellah et al. Journal of Pharmaceutical Technology \& Drug Research 2014,

http://www.hoajonline.com/journals/pdf/2050-120X-3-2.pdf

thereby reducing zeta potential of fabricated polyplexes [27].

\section{Cellular safety}

Clinical success of gene delivery systems critically depends on an acceptable safety profile as well as therapeutic efficacy. Undesired cellular effect induced by polyplexes may result from chemical features of excipients use to fabricate these colloidal drug delivery systems and/or from physicochemical properties associated with these electrostatically stabilized nanoassemblies. The impact of pHPMA-b-pDMAEMA and ERL particles fabricated in the presence and absence of pDNA was assessed on HeLa cell viability by quantifying total cellular ATP levels using the CellTiter-Glo ${ }^{\circledR}$ assay.

Irrespective whether or not pDNA was included in the experiment, pHPMA-b-pDMAEMA did not significantly compromise cellular safety up to concentrations required for $\mathrm{N} / \mathrm{P}=4$ polyplexes (Figure 4A). In contrast, exposure of cells to increasing ERL concentrations significantly reduced cell viability by $\sim 20 \%$ when compared to media control using polymer concentrations required to fabricate polyplexes at $\mathrm{N} / \mathrm{P}=4$ (Figure 4B). However, inclusion of pDNA ameliorated the observed negative effect of ERL on cell viability (Figure 4B). Electrostatically stabilized pDNA/polymer complexes not only reduce excess positive charge of ERL but also alter the size distribution of these colloids that interact with the cells. Inclusion of pDNA produced larger particles than ERL alone (Table 2), which is hypothesized to decrease cellular uptake and, consequently, cytotoxicity [28]. Previously, it was reported that a high positive charge density in polymers used to fabricate nonviral gene delivery systems compromises cell viability [29]. pHPMA-b-pDMAEMA carries on a molar basis approximately 3-times the number of cationic centers than ERL. As cellular safety of HeLa cells was not compromised after incubation with pHPMA-b-pDMAEMA-containing polyplexes, it seems that particle size and zeta potential have a greater impact on viability of this cancer cell line than the positive charge density of the polymer. These findings are consistent with results reported earlier by Cai and co-workers [19].

\section{Polyplex buffering capacity}

Transgene expression after incubation with a nonviral gene delivery system critically depends on effective release of internalized polyplexes from the endosome [30]. During the transition from early to late endosome, the luminal $\mathrm{pH}$ of endocytic vesicles rapidly decreases to approximately $\mathrm{pH} 5$ in support of physiological degradation. The presence of weak bases in the endosomal compartment neutralizes ATPasegenerated protons and increases the osmotic pressure that ultimately induces vesicle rupture [31]. This "proton sponge" effect is predicted to enhance endosomal escape of nonviral gene delivery systems, thereby augmenting transfection efficiency. Experimentally, the buffer capacity is considered a suitable parameter to predict "proton sponge" effects of cationic polymers. The results from acid-base titrations of

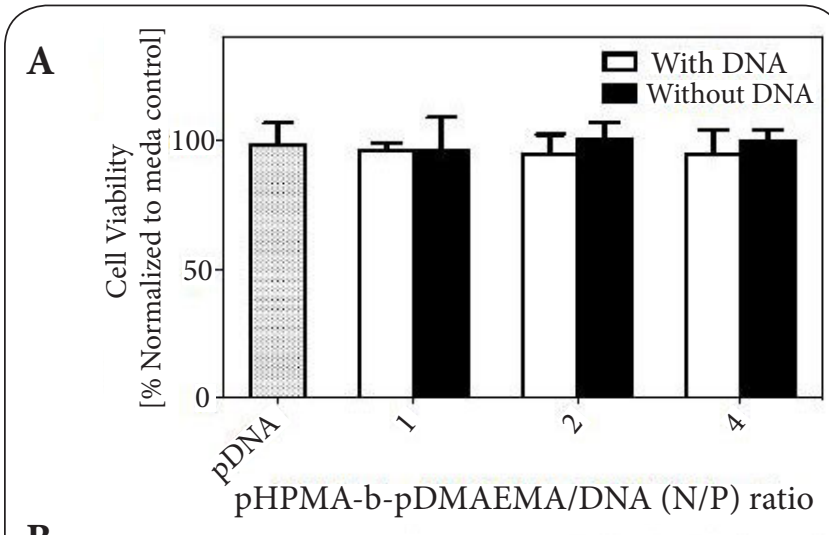

B

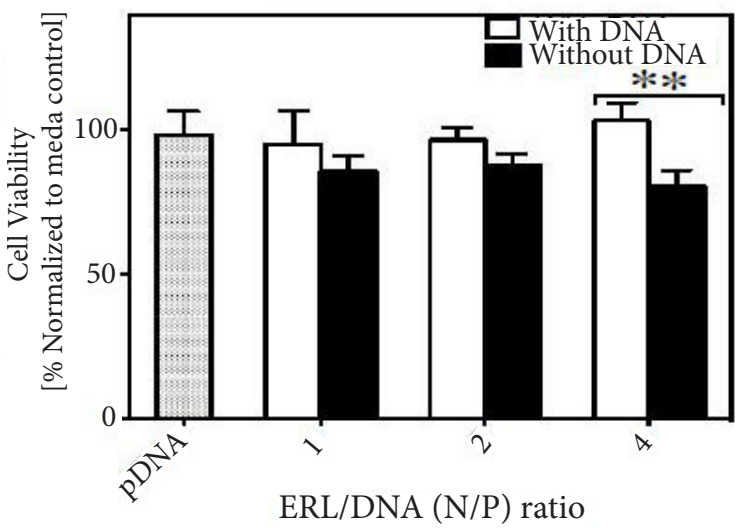

Figure 4. Cellular safety of methacrylate-based polymers in HeLa cells in the presence and absence of pDNA.

Nanoparticles were formed in PBS or SFM with and without $1 \mu \mathrm{g}$ of $\mathrm{pAcGFP} 1-\mathrm{C} 1 \mathrm{using}$ polymer compositions equivalent to $\mathrm{N} / \mathrm{P}=1,2$ and 4 , respectively. HeLa cells were incubated for $4 \mathrm{hrs}$ in SFM with nanoassemblies fabricated with pHPMAb-pDMAEMA (Panel A) and ERL (Panel B). Cell viability was quantified $48 \mathrm{hrs}$ post-treatment using the 2 CellTiter$\mathrm{Glo}^{\circ}$ assay. Results are normalized to media control and shown as mean $\pm \operatorname{SD}(\mathrm{n}=3)$. ${ }^{\star}$ Significantly different $(\mathrm{p}<0.05)$.

an unbuffered $\mathrm{NaCl}$ solution demonstrate rapid decrease in solution $\mathrm{pH}$ upon addition of $0.1 \mathrm{~N} \mathrm{HCl}$ increments (Figure 5). PEI25k, which exhibits an excellent buffering capacity in the lysosomal $\mathrm{pH}$ range between $\mathrm{pH}$ 5.0-7.4, effectively delays rapid acidification that correlates with high transfection efficiency in vitro [29]. The $\mathrm{pH}$ profile of pHPMA-b-pDMAEMA after incremental $0.1 \mathrm{~N} \mathrm{HCl}$ additions demonstrated a similar buffer capacity as measured for the PEI25k solution, which implies an effective "proton sponge" effect under endosomerelevant acidic conditions. These results suggest that secondary and tertiary amines present in pHPMA-b-pDMAEMA are freely accessible to protonation despite the methacrylamide polymer backbone. Buffer capacity of solutions prepared with ERL was significantly reduced due to the presence of quaternary ammonium groups that are unable to change the degree of ionization as a function of environmental $\mathrm{pH}$. The rapid decrease in $\mathrm{pH}$ profile observed with $\mathrm{ERL}$ following $\mathrm{HCl}$ addition implies minimal buffer capacity and, consequently, 
inefficient endosomal escape mediated by "proton sponge" effects. This endosomal escape inhibition due to the lack of buffering tertiary amine moieties was reported previously $[32,33]$.

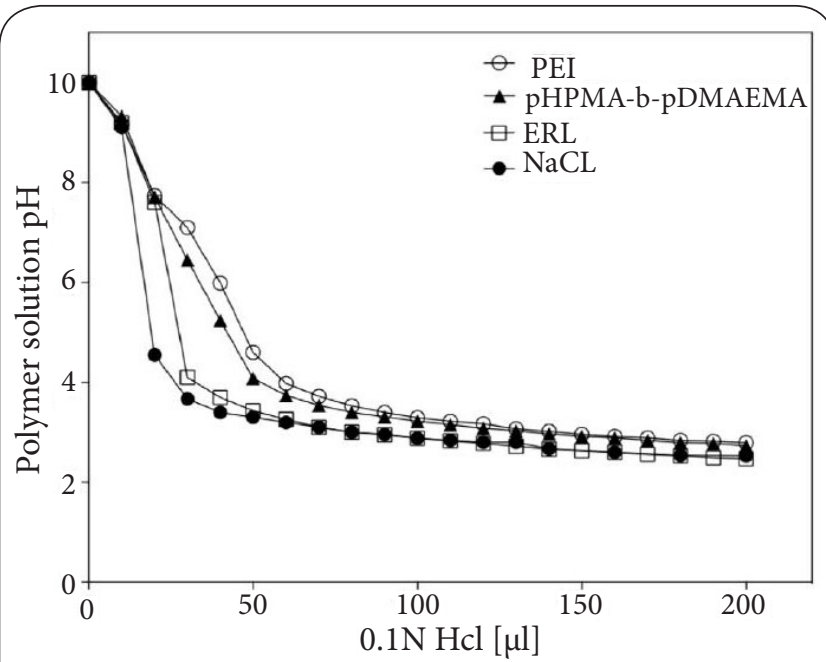

Figure 5. Polymer buffer capacity. Titration of a basic $20 \mu \mathrm{g} /$ mL solution of pHPMA-bpDMAEMA ( $\boldsymbol{\Delta})$, ERL ( $\square$ ), PEI25k $(\bigcirc)$, and $5 \mathrm{mM} \mathrm{NaCl}(\bullet)$ was performed using $0.1 \mathrm{~N} \mathrm{HCl}$. The $\mathrm{pH}$ value of the mixture was measured after each addition of $\mathrm{HCl}$ increment. Results are shown as average $\pm \mathrm{SD}$ $(n=3)$.

\section{In vitro transfection efficiency}

To assess transfection efficiency of polyplexes prepared with the different methacrylate-based polymers, HeLa cells were incubated with these nonviral delivery systems of the PAcGFP1$\mathrm{C} 1$ reporter gene in the presence and absence of $10 \% \mathrm{FBS}$. The commercially available TurboFect ${ }^{\mathrm{TM}}$ transfection reagent was used as positive control. Visual quantitation of the percentage of GFP-expressing cells under various conditions is summarized in Figure 6. Combination of the PAcGFP1-C1 expression plasmid with TurboFect ${ }^{\mathrm{TM}}$ according to manufacturer's recommendation resulted in a mean transfection efficiency of nearly $80 \%$. No transgene expression was observed with pDNA only. Polyplexes prepared with $E R L$ up to $N / P=4$ failed to induce effective GFP expression, which was primarily attributed to the limited buffering capacity of this quaternary amine-containing polymer under acidic conditions that may have restricted effective endosomal escape. In general, pDNA association complexes fabricated with the various methacrylate-based polymers at $\mathrm{N} / \mathrm{P}=1$ were ineffective in inducing significant transgene expression. It is hypothesized that weak interactions at charge neutrality facilitate rapid dissociation of the electrostatically stabilized nanoassemblies in the presence of polyanions at the cell surface [34]. Polyplexes comprised of pHPMA-b-pDMAEMA resulted in a high GFP expression (Figure 6). Comparison of different N/P ratios demonstrated

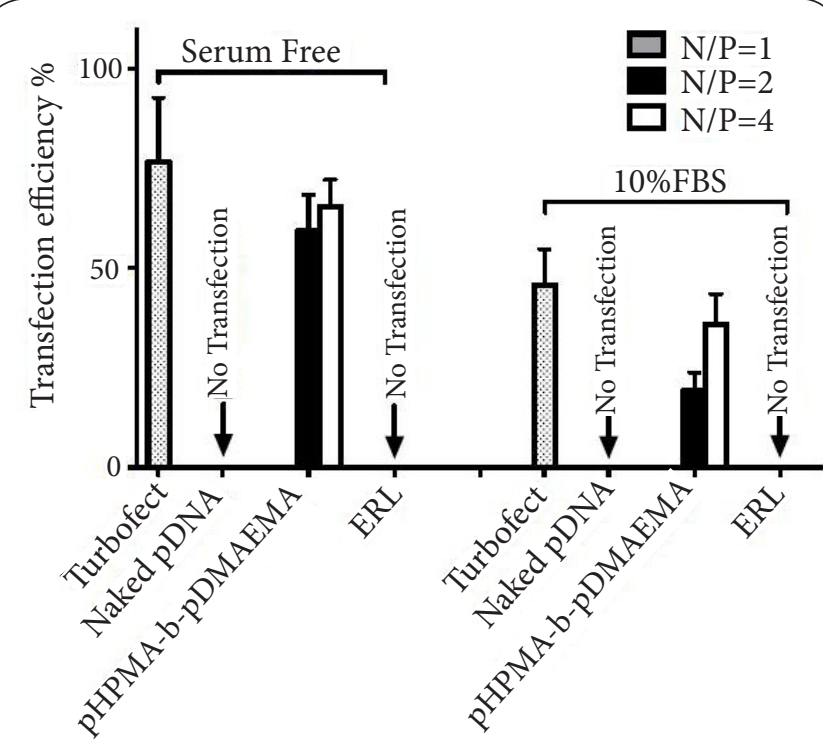

Figure 6. Transfection efficiency of methacrylate-based polyplexes in HeLa cells in the presence and absence of serum. Nanoassemblies were formed in PBS or SFM with $1 \mu \mathrm{g}$ of pAcGFP1-C1 using polymer compositions equivalent to N/ $\mathrm{P}=1,2$ and 4, respectively. HeLa cells were incubated for 4 hrs in the presence and absence of $10 \%$ FBS with polyplexes fabricated with pHPMA-b-pDMAEMA and ERL. TurboFect ${ }^{\mathrm{Tm}} /$ pDNA polyplexes prepared according to manufacturer's instructions were used as positive control. GFP-expressing cells were identified $48 \mathrm{hrs}$ post-treatment by confocal microscopy. Transfection efficiency for each polymer was quantified by determining the percentage of GFP-positive cells in three random sections. Data are shown as mean $\pm S D(n=3)$.

maximal transfection efficiency of HeLa cells around $65 \%$ at $\mathrm{N} / \mathrm{P}=4$, which was not significantly different from polyplexes prepared with TurboFect ${ }^{\mathrm{TM}}$.

Transfection efficiency of gene delivery systems under in vivo conditions is generally reduced due surface adsorption of plasma proteins that can alter surface charge and hydrodynamic radius of polyplexes [35]. To assess the impact of plasma proteins on $\mathrm{PAcGFP}-1 / \mathrm{C} 1$ polyplexes fabricated with different methacrylate-based catiomers, transfection efficiency in HeLa cells was determined in the presence of $10 \%$ FBS. Polyplexes fabricated at $\mathrm{N} / \mathrm{P}=1$ and $\mathrm{ERL}$ polyplexes remained ineffective in inducing significant transgene expression. This implies that proposed surface adsorption of plasma proteins does not enhance but rather impede effective internalization and/or endosomal escape. In comparison to the results obtained with the same pHPMA-b-pDMAEMA polyplexes in the absence of serum, inclusion of plasma proteins reduced transfection efficiency by at least $30 \%$ (Figure 6). The transfection efficiency of pHPMA-b-pDMAEMA polyplexes at $\mathrm{N} / \mathrm{P}=4$ was $36 \pm 8 \%$, which is not significantly different from the results using the positive control TurboFect ${ }^{\mathrm{TM}}$. Despite the negative effect of serum on transfection efficiency, the predicted impact of pHPMAb-pDMAEMA polyplexes as nonviral gene delivery systems 
remains superior to those fabricated with the FDA-approved ERL polymer.

\section{Conclusion}

Comparative assessment of methacrylate-containing cationic polymers revealed that polyplex formation with pAcGFP1-C1 plasmid is significantly influenced by the composition of the polymer and the fabrication vehicle. Physicochemical properties such as size and zeta potential of electrostatically stabilized nanoassemblies depend on charge density engineered into the polymer. In the absence of pDNA, cellular safety profile of secondary and tertiary amine-containing pHPMA-b-pDMAEMA polymer was superior to that of quaternary ammonium-containing ERL. However, electrostatically stabilized association complexes with pDNA ameliorate this material-dependent cytotoxicity effect. Polyplexes fabricated with pHPMA-b-pDMAEMA at N/P $\geq 2$ successfully induced transgene expression in HeLa cells in the presence and absence of serum, which may be facilitated by an effective endosomal escape due to substantial buffering capacity associated with a "proton sponge" effect of secondary and tertiary amino groups. Quaternary amine-containing ERL polyplexes, in contrast, failed to induce GFP expression in HeLa cells even in the absence of $10 \%$ FBS. Future in vivo studies will have to demonstrate whether secondary and tertiary amine-containing methacrylate-based polymers such as pHPMA-b-pDMAEMA provide a significant advantage with respect to safety and/or efficacy of nonviral gene delivery systems that would justify the additional time and expense required to obtain FDA regulatory approval for this novel excipient.

\section{Competing interests}

The authors declare that they have no competing interests.

\section{Authors' contributions}

\begin{tabular}{|l|c|c|c|c|c|c|c|c|}
\hline Authors' contributions & NHA & SJP & LT & NA & MME & GNF & EAI & GMP \\
\hline Research concept and design & $\checkmark$ & -- & -- & -- & $\checkmark$ & $\checkmark$ & $\checkmark$ & $\checkmark$ \\
\hline Collection and/or assembly of data & $\checkmark$ & $\checkmark$ & $\checkmark$ & $\checkmark$ & $\checkmark$ & $\checkmark$ & $\checkmark$ & $\checkmark$ \\
\hline Data analysis and interpretation & $\checkmark$ & -- & -- & -- & -- & -- & -- & $\checkmark$ \\
\hline Writing the article & $\checkmark$ & -- & -- & -- & -- & -- & -- & -- \\
\hline Critical revision of the article & -- & -- & -- & -- & -- & -- & -- & $\checkmark$ \\
\hline Final approval of article & $\checkmark$ & -- & -- & -- & -- & -- & -- & $\checkmark$ \\
\hline Statistical analysis & $\checkmark$ & -- & -- & -- & -- & -- & -- & $\checkmark$ \\
\hline
\end{tabular}

\section{Acknowledgement}

The authors would like to thank Dr. Helen Jones and Charles Klanke (Cincinnati Children's Hospital Medical Center, Cincinnati, USA) for providing the GFP-expression plasmid. This research was supported in part by a predoctoral fellowship from the Egyptian Ministry of Higher Education awarded to Noura H. Abd Ellah.

\section{Publication history}

EIC: James Radosevich, University of Illinois, USA. Received: 10-Oct-2014 Final Revised: 24-Nov-2014 Accepted: 05-Dec-2014 Published: 11-Dec-2014

\section{References}

1. Kao CY, Yang SJ, Tao MH, Jeng YM, Yu IS and Lin SW. Incorporation of the factor IX Padua mutation into FIX-Triple improves clotting activity in vitro and in vivo. Thromb Haemost. 2013; 110:244-56. | Article | PubMed

2. Wang T, Upponi JR and Torchilin VP. Design of multifunctional nonviral gene vectors to overcome physiological barriers: dilemmas and strategies. Int J Pharm. 2012; 427:3-20. | Article I PubMed

3. Abdelhady HG, Allen S, Davies MC, Roberts CJ, Tendler SJ and Williams PM. Direct real-time molecular scale visualisation of the degradation of condensed DNA complexes exposed to DNase I. Nucleic Acids Res. 2003; 31:4001-5. | Article | PubMed Abstract | PubMed Full Text

4. Wang Y, Canine BF and Hatefi A. HSV-TK/GCV cancer suicide gene therapy by a designed recombinant multifunctional vector. Nanomedicine. 2011; 7:193-200. | Article | PubMed Abstract | PubMed Full Text

5. Behr JP. Gene transfer with synthetic cationic amphiphiles: prospects for gene therapy. Bioconjug Chem. 1994; 5:382-9. | Article I PubMed

6. Burke RS and Pun SH. Extracellular barriers to in Vivo PEI and PEGylated PEI polyplex-mediated gene delivery to the liver. Bioconjug Chem. 2008 19:693-704. | Article | PubMed

7. Zhao XB and Lee RJ. Tumor-selective targeted delivery of genes and antisense oligodeoxyribonucleotides via the folate receptor. Adv Drug Deliv Rev. 2004; 56:1193-204. I Article I PubMed

8. Wagner M, Pietsch C, Tauhardt L, Schallon A and Schubert US. Characterization of cationic polymers by asymmetric flow field-flow fractionation and multi-angle light scattering-A comparison with traditional techniques. J Chromatogr A. 2014; 1325:195-203. | Article | PubMed

9. Wang J, Gao SJ, Zhang PC, Wang S, Mao HQ and Leong KW. Polyphosphoramidate gene carriers: effect of charge group on gene transfer efficiency. Gene Ther. 2004; 11:1001-10. | Article | PubMed

10. Reschel T, Konak C, Oupicky D, Seymour LW and Ulbrich K. Physical properties and in vitro transfection efficiency of gene delivery vectors based on complexes of DNA with synthetic polycations. J Control Release. 2002; 81:201-17. | Article | PubMed

11. Yang XC, Chai MY, Zhu Y, Yang WT and Xu FJ. Facilitation of gene transfection with well-defined degradable comb-shaped poly(glycidyl methacrylate) derivative vectors. Bioconjug Chem. 2012; 23:618-26. | Article I PubMed

12. van de Wetering $P$, Cherng JY, Talsma H, Crommelin DJ and Hennink WE. 2-(Dimethylamino)ethyl methacrylate based (co)polymers as gene transfer agents. J Control Release. 1998; 53:145-53. | Article I PubMed

13. Hunter AC. Molecular hurdles in polyfectin design and mechanistic background to polycation induced cytotoxicity. Adv Drug Deliv Rev. 2006; 58:1523-31. | Article | PubMed

14. van de Wetering JK, Elfring $\mathrm{RH}$, Oosterlaken-Dijksterhuis MA, Mol JA, Haagsman HP and Batenburg JJ. Perinatal expression of IGFBPs in rat lung and its hormonal regulation in fetal lung explants. Am J Physiol. 1997; 273:L1174-81. | Article | PubMed

15. Duvall CL, Convertine AJ, Benoit DS, Hoffman AS and Stayton PS. Intracellular delivery of a proapoptotic peptide via conjugation to a RAFT synthesized endosomolytic polymer. Mol Pharm. 2010; 7:468-76. | Article | PubMed Abstract | PubMed Full Text

16. Benns JM, Choi JS, Mahato RI, Park JS and Kim SW. pH-sensitive cationic polymer gene delivery vehicle: N-Ac-poly(L-histidine)-graft-poly(Llysine) comb shaped polymer. Bioconjug Chem. 2000; 11:637-45. I Article | PubMed

17. Eidi $H$, Joubert $O$, Nemos $C$, Grandemange $S$, Mograbi B, Foliguet B, Tournebize J, Maincent P, Le Faou A, Aboukhamis I and Rihn BH. Drug delivery by polymeric nanoparticles induces autophagy in macrophages. Int J Pharm. 2012; 422:495-503. I Article I PubMed

18. Huang YP, Lin IJ, Chen CC, Hsu YC, Chang CC and Lee MJ. Delivery of small interfering RNAs in human cervical cancer cells by polyethyleniminefunctionalized carbon nanotubes. Nanoscale Res Lett. 2013; 8:267. | Article I PubMed Abstract I PubMed Full Text 
19. Cai X, Dong C, Dong H, Wang G, Pauletti GM, Pan X, Wen H, Mehl I, Li Y and Shi $D$. Effective gene delivery using stimulus-responsive catiomer designed with redox-sensitive disulfide and acid-labile imine linkers. Biomacromolecules. 2012; 13:1024-34. | Article | PubMed

20. Haynes M, Garrett RA and Gratzer WB. Structure of nucleic acid-poly base complexes. Biochemistry. 1970; 9:4410-6. | Article | PubMed

21. Vamanu $\mathrm{Cl}$, Hol PJ, Allouni ZE, Elsayed S and Gjerdet NR. Formation of potential titanium antigens based on protein binding to titanium dioxide nanoparticles. Int J Nanomedicine. 2008; 3:69-74. I PubMed Abstract | PubMed Full Text

22. de Wolf HK, de Raad M, Snel C, van Steenbergen MJ, Fens MH, Storm $G$ and Hennink WE. Biodegradable poly(2-dimethylamino ethylamino) phosphazene for in vivo gene delivery to tumor cells. Effect of polymer molecular weight. Pharm Res. 2007; 24:1572-80. | Article | PubMed Abstract | PubMed Full Text

23. Amjad M. Qandil, SMA, Enas A. Al Ani, AEY and Obaidat AA. Sustainedrelease diclofenac potassium orally disintegrating tablet incorporating eudragit ERL/ERS: possibility of specific diclofenac-polymer interaction. J Pharm Invest. 2013; 43:171-183. | Article

24. Jiang QY, Lai LH, Shen J, Wang QQ, Xu FJ and Tang GP. Gene delivery to tumor cells by cationic polymeric nanovectors coupled to folic acid and the cell-penetrating peptide octaarginine. Biomaterials. 2011; 32:725362. | Article | PubMed

25. van de Wetering P, Cherng J-Y, Talsma $\mathrm{H}$ and Hennink WE. Relation between transfection efficiency and cytotoxicity of poly(2(dimethylamino)ethyl methacrylate)/plasmid complexes. J Control Release. 1997; 49:59-69. | Article

26. Palermo EF, Lee DK, Ramamoorthy $A$ and Kuroda K. Role of cationic group structure in membrane binding and disruption by amphiphilic copolymers. J Phys Chem B. 2011; 115:366-75. I Article I PubMed Abstract | PubMed Full Text

27. Oupicky D, Howard KA, Konak C, Dash PR, Ulbrich K and Seymour LW. Steric stabilization of poly-L-Lysine/DNA complexes by the covalent attachment of semitelechelic poly[N-(2-hydroxypropyl) methacrylamide]. Bioconjug Chem. 2000; 11:492-501. | Article | PubMed

28. Prabha S, Zhou WZ, Panyam J and Labhasetwar V. Size-dependency of nanoparticle-mediated gene transfection: studies with fractionated nanoparticles. Int J Pharm. 2002; 244:105-15. | Article | PubMed

29. Fischer D, Bieber T, Li Y, Elsasser HP and Kissel T. A novel non-viral vector for DNA delivery based on low molecular weight, branched polyethylenimine: effect of molecular weight on transfection efficiency and cytotoxicity. Pharm Res. 1999; 16:1273-9. | Article | PubMed

30. Elouahabi $A$ and Ruysschaert JM. Formation and intracellular trafficking of lipoplexes and polyplexes. Mol Ther. 2005; 11:336-47. I Article | PubMed

31. Boussif O, Lezoualc'h F, Zanta MA, Mergny MD, Scherman D, Demeneix B and Behr JP. A versatile vector for gene and oligonucleotide transfer into cells in culture and in vivo: polyethylenimine. Proc Natl Acad Sci U S A. 1995; 92:7297-301. | Article I PubMed Abstract | PubMed Full Text

32. van de Wetering $P$, Moret EE, Schuurmans-Nieuwenbroek NM, van Steenbergen MJ and Hennink WE. Structure-activity relationships of water-soluble cationic methacrylate/methacrylamide polymers for nonviral gene delivery. Bioconjug Chem. 1999; 10:589-97. | Article | PubMed

33. Lee JH, Lim YB, Choi JS, Lee Y, Kim TI, Kim HJ, Yoon JK, Kim K and Park JS. Polyplexes assembled with internally quaternized PAMAM-OH dendrimer and plasmid DNA have a neutral surface and gene delivery potency. Bioconjug Chem. 2003; 14:1214-21. I Article I PubMed

34. Zaghloul EM, Viola JR, Zuber G, Smith $\mathrm{Cl}$ and Lundin KE. Formulation and delivery of splice-correction antisense oligonucleotides by amino acid modified polyethylenimine. Mol Pharm. 2010; 7:652-63. | Article | PubMed

35. Buyens K, Lucas B, Raemdonck K, Braeckmans K, Vercammen J, Hendrix J, Engelborghs Y, De Smedt SC and Sanders NN. A fast and sensitive method for measuring the integrity of siRNA-carrier complexes in full human serum. J Control Release. 2008; 126:67-76. | Article | PubMed

\section{Citation:}

Abd Ellah NH, Potter SJ, Taylor L, Ayres N, Elmahdy MM, Fetih GN, Ibrahim E-SA and Pauletti GM. Safety and efficacy of amine-containing methacrylate polymers as nonviral gene delivery vectors. J Pharm Technol Drug Res. 2014; 3:2.

http://dx.doi.org/10.7243/2050-120X-3-2 